\title{
MEASUREMENT OF INTRATRACHEAL OXYGEN CONCENTRATIONS DURING FACE MASK ADMINISTRATION OF OXYGEN: A MODIFICATION FOR IMPROVED CONTROL
}

\author{
H.R. Wexler, A. Aberman, A.A. Scott, and J.D. Cooper
}

A rational MANAGEMENT of respiratory insufficiency requires knowledge and control of the inspired oxygen concentration $\left(\mathrm{F}_{\mathrm{I}_{2}}\right)$ delivered to the patient. Knowledge of the $\mathrm{F}_{\mathrm{O}_{2}}$ is required for estimation of physiological shunt, based on the alveolar-arterial oxygen difference. ${ }^{1}$ Control of the oxygen concentration is required if one is to avoid unnecessarily high inspired oxygen concentrations, with the attendant risk of pulmonary oxygen toxicity. ${ }^{2}$

When the patient is breathing through a closed system, such as through a tracheal tube, the inspired oxygen concentration can be easily measured and controlled. When oxygen is delivered by an open face mask, however, the true inspired oxygen concentration cannot readily be measured and may be influenced by factors other than the oxygen concentration delivered to the mask. These variables include the patient's respiratory rate and pattern of breathing as well as the design and fit of the mask used and the flow rate of the oxygen delivered to the mask.

Although the inspired oxygen concentration has been estimated under these circumstances, clinical data is lacking regarding the exact oxygen concentration delivered to the lungs, when oxygen is administered through such open systems..$^{3,4,8}$

In this study, the intratracheal inspired oxygen concentration was measured directly in spontaneously breathing patients receiving oxygen through a plastic face mask. The variables affecting the $\mathrm{FI}_{\mathrm{O}_{2}}$ under these circumstances were determined. Mechanical ${ }^{6}$ and mathematical ${ }^{5,9}$ models were used to study the effect of the variables in an attempt to provide improved predictability and control of the $\mathrm{F}_{\mathrm{O}_{2}}$. The result has been the development of a modified oxygen face mask and construction of a nomogram for this mask which aids in the estimation of the true $\mathrm{F}_{\mathrm{O}_{2}}$ delivered to the patient.

\section{METHODS}

\section{Clinical Measurements}

Intratracheal oxygen concentration was measured directly in patients receiving oxygen by face mask in the Respiratory Care Unit of the Toronto General

From the Respiratory Care Unit of the Toronto General Hospital, the Department of Medicine, Mount Sinai Hospital, and the Departments of Surgery, Medicine, and Anaeshesia, of the University of Toronto.

Supported in part by grants from Ontario Thoracic Society No. 3-357-289-30, National Sanitarium Association No. 3-333-289-90.

Reprint requests to: Dr. J.D. Cooper, 118 University Wing, Toronto General Hospital, Toronto, Ontario. 


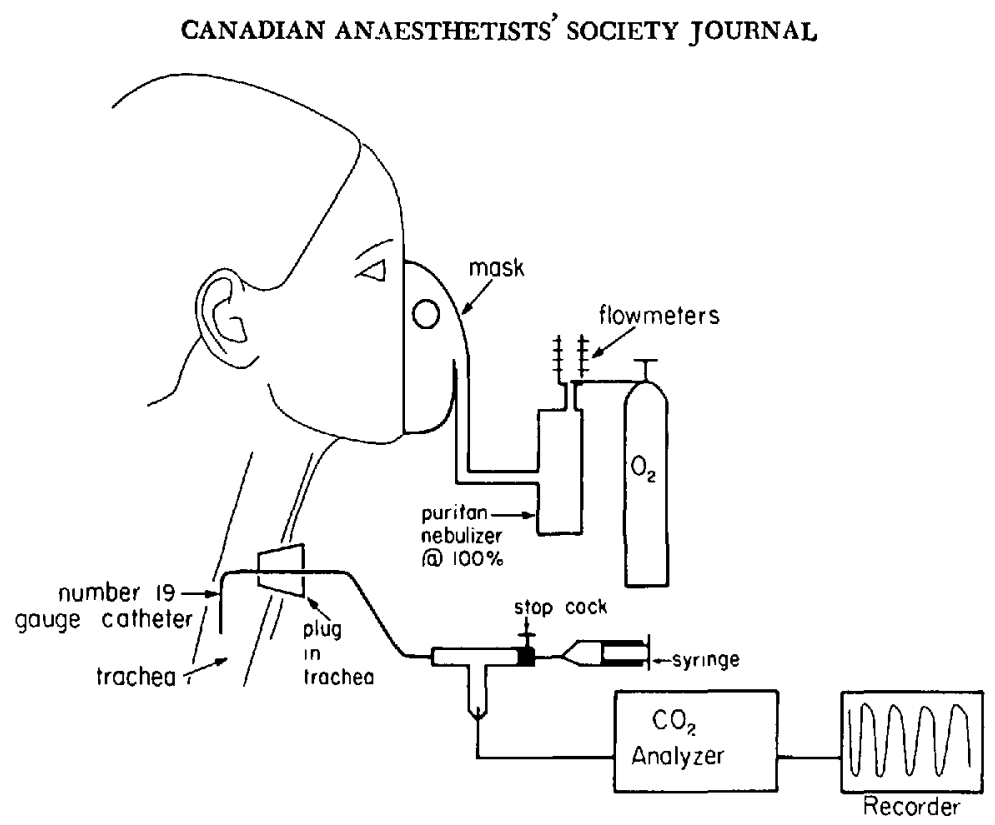

Figure 1. Patient sampling system. See text for explanation.

Hospital. Each patient had had a tracheostomy tube removed several days earlier but was breathing spontaneously through the upper airway with the residual stoma covered by an occlusive dressing. A No. 19 catheter was passed through this residual stoma into the distal trachea through a small plastic plug which completely occluded the rest of the stoma. The intratracheal catheter was connected to a small $Y$ connector. One limb of the $Y$ connector was used for withdrawing samples of tracheal gas for oxygen analysis. The other limb was connected to a Beckman $\mathrm{LB}-1$ rapid $\mathrm{CO}_{2}$ analyzer set to sample at $500 \mathrm{cc}$ per minute. The output of the $\mathrm{CO}_{2}$ analyzer was continuously recorded on a Mosely strip chart recorder. The total volume of the catheter, $Y$ piece and connecting tubing, was $3.5 \mathrm{cc}$. Figure 1 illustrates the sampling system used.

One hundred per cent oxygen was delivered to the patient through a Puritan nebulizer using calibrated flow meters. Wide bore tubing ( $\left.\varkappa^{\prime \prime}\right)$ connected the nebulizer to a standard aerosol oxygen mask. ${ }^{*}$ Figure 2 illustrates the mask and tubing used.

The continuous recording of the $\mathrm{CO}_{2}$ concentration in the trachea (see Figure 3 ) served as a tracing of the respiratory cycle and permitted measurement of the respiratory rate and the duration of the inspiratory phase of each respiratory cycle (the inspiratory fraction).

Samples of tracheal gas for oxygen analysis were aspirated into $50 \mathrm{cc}$ plastic syringes during several consecutive inspiratory cycles, at a time when respiration was stable. The sampled gas was immediately analyzed using a Servomex Mark II paramagnetic oxygen analyzer. We had previously determined that there was no diffusion of oxygen into or out of the syringes during the period required for sampling and measurement.

"Medicon Plastics-Upland, California. 


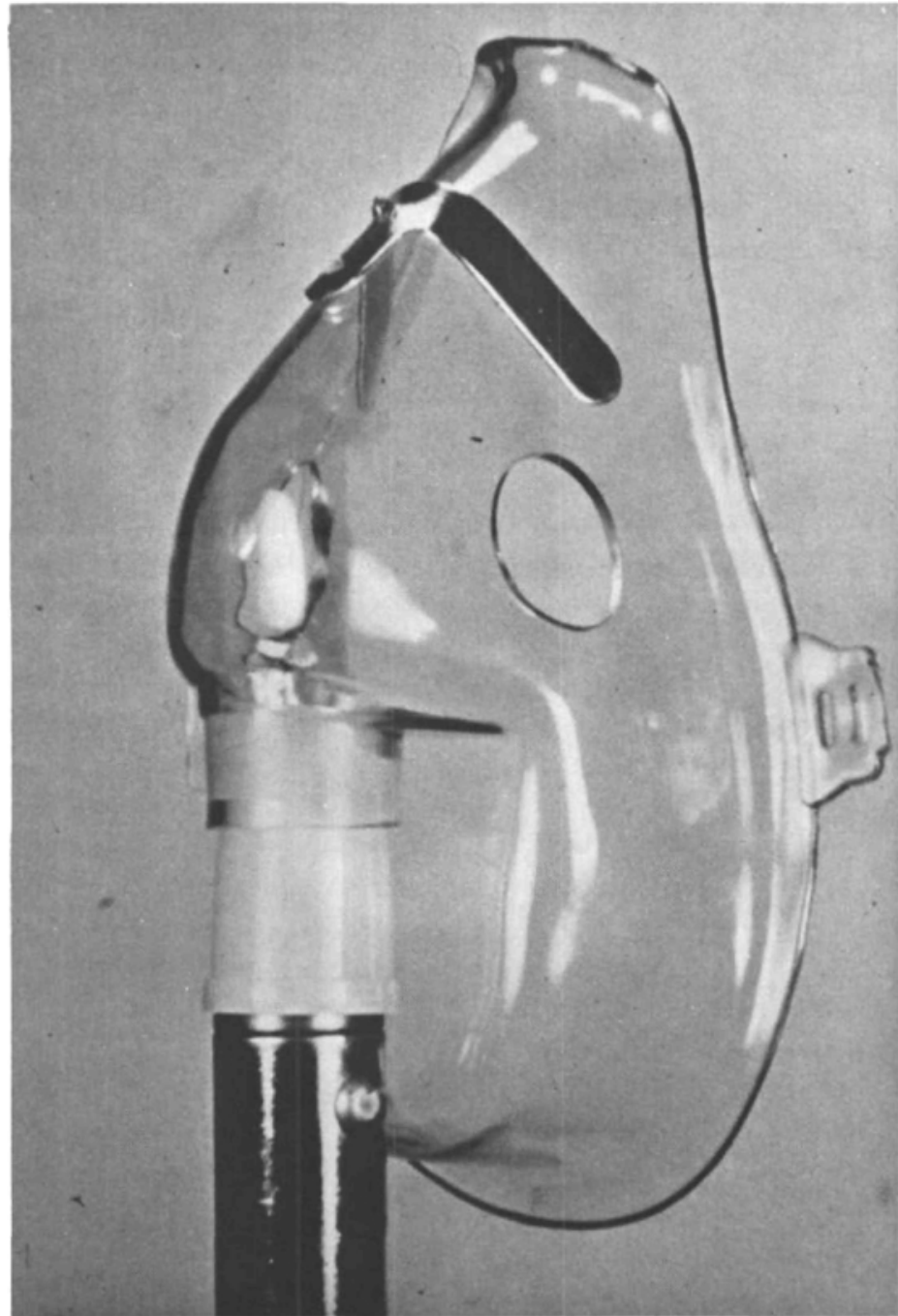

Figure 2. Standard plastic aerosol mask. Medecon Plastics Division, C.R. Bard Inc., Upland California.

In each patient the flow rate of 100 per cent oxygen delivered to the mask was increased from five litres per minute to 30 litres per minute in five-litre increments. At each of these six flow rates, tracheal oxygen concentration was measured during the inspiratory phase.

The patient's minute ventilation was measured with a Wright respirometer attached to an occlusive anaesthetic face mask. The minute ventilation was measured both immediately before and immediately after the measurements of the tracheal oxygen concentrations delivered by the plastic face mask. The duplicate values of minute ventilation proved to be quite similar, the difference between the two being less than $600 \mathrm{cc}$ in each patient. The average of the twominute ventilation determinations was used for subsequent calculations. Tidal 

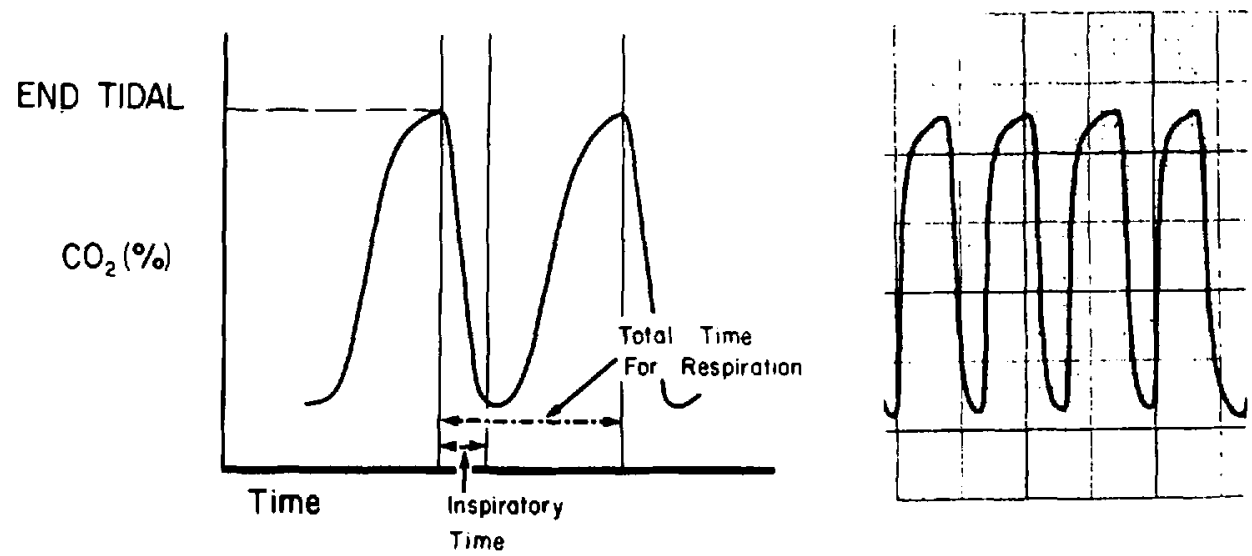

Figure 3. Sample recording of tracheal $\mathrm{CO}_{2}$. On the right is an actual record. On the Jeft is a schematic analysis of the respiratory cycle - see text.

volume was calculated by dividing the minute ventilation by the respiratory frequency.

\section{Mechanical Model}

To evaluate the effect of the variables which might affect the inspired oxygen concentration in patients, a mechanical model of the ventilatory system was constructed (See Figure 4). A Harvard sine-wave pump was used to simulate respiration. A standard plastic aerosol mask was mounted on a firm backing and attached to the Harvard pump with a tube the size of a normal human trachea. A No. 19 catheter was used to sample the $\mathrm{F}_{\mathrm{I}_{2}}$ in the mechanical "trachea." One hundred per cent oxygen was delivered through the same system of flow meters

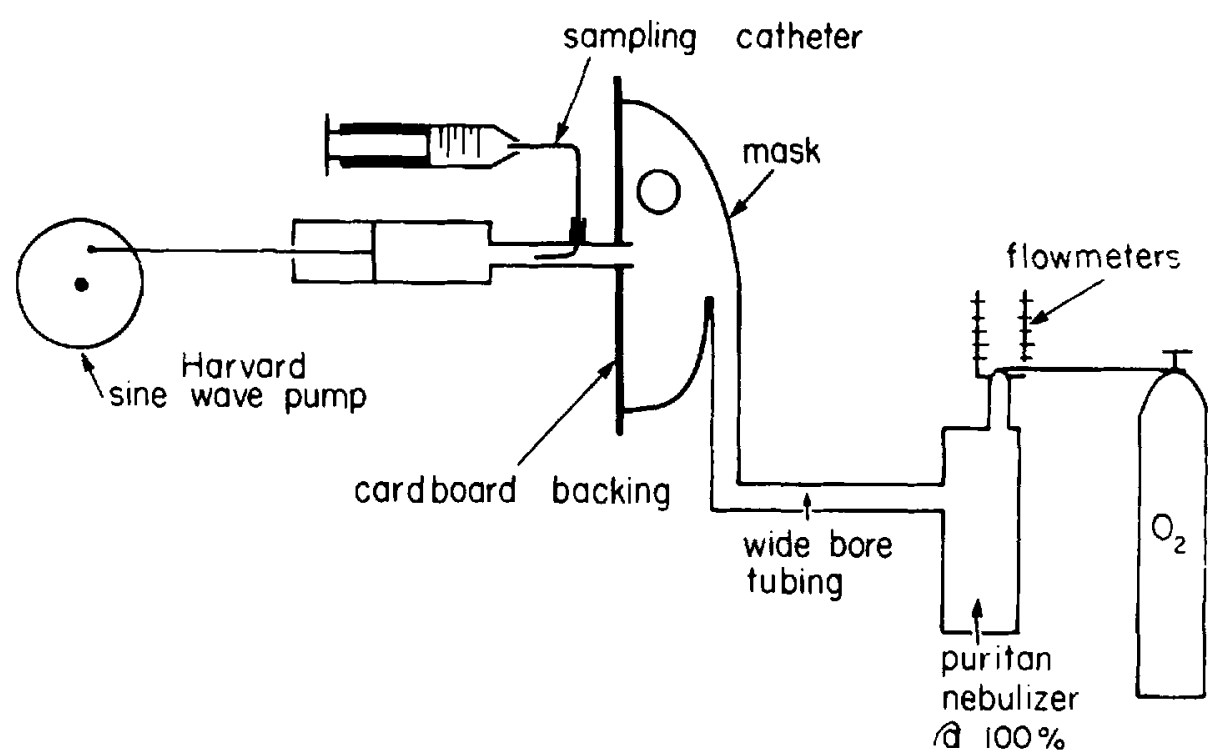

Ficure 4. Schematic diagram of mechanical model used to simulate respiration. 


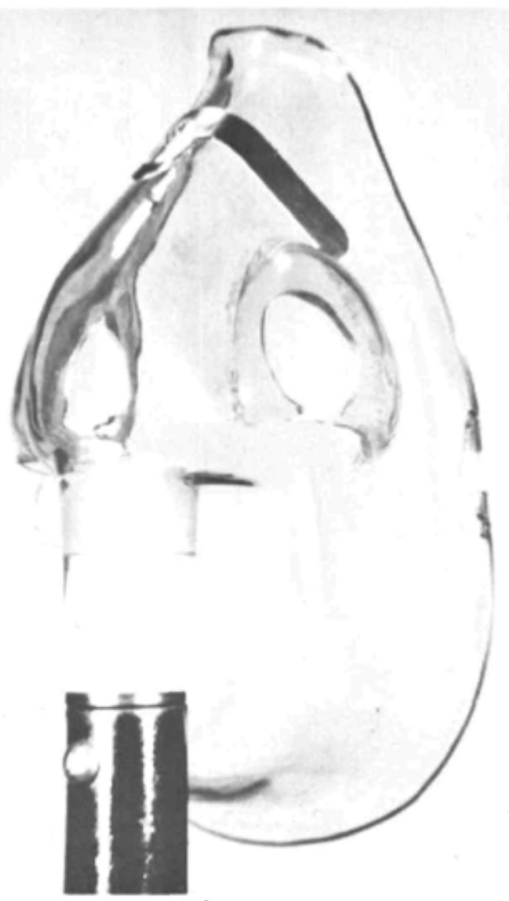

(a)

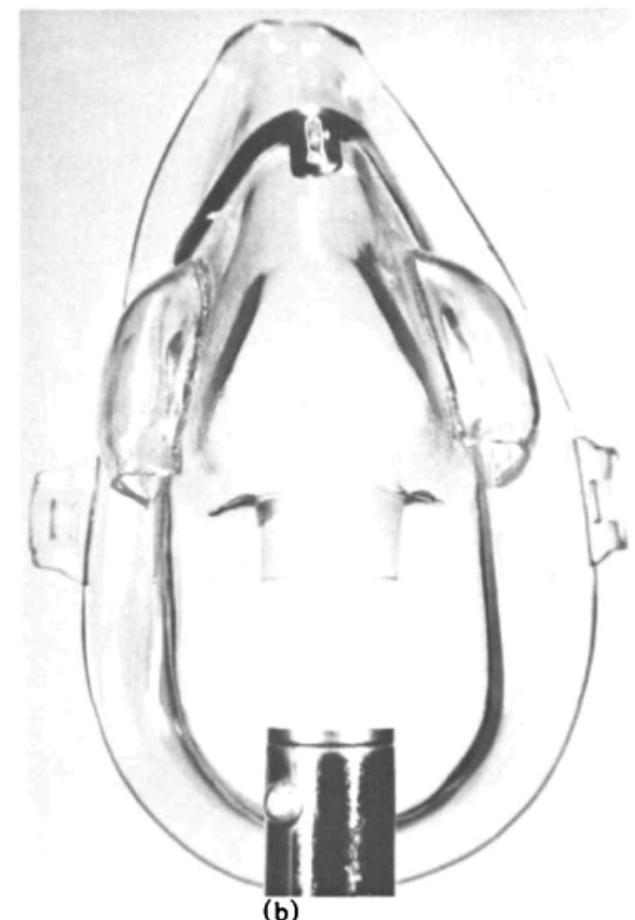

(b)

Frgunes 5a, 5b. Modified aerosol mask. Hooded shields which are open at the bottom have been placed over the side holes of the mask.

and Puritan nebulizer used for the clinical studies. The Harvard Pump was set to deliver a tidal volume of $600 \mathrm{cc}$ at a respiratory frequency of 15 cycles per second and an inspiratory fraction of 0.5 of the respiratory cycle. Oxygen flow rates to the mask were varied from 5 litres to 30 litres per minute as in the clinical studies.

\section{Effect of Surrounding Air Currents}

The studies using the mechanical model were carried out in both a very still environment and in one containing air currents generated by a small fan placed six feet from the face mask. To reduce the effects of turbulence on the mixing of room air with oxygen delivered to the face mask, a modified oxygen mask was constructed by placing shields over the side-holes as illustrated in Figure 5. These shields reduce the turbulence around the side holes in the mask without interfering in any way with the rapid flow of gas into or out of the mask. This modified mask was compared with the standard unshielded mask, using both the mechanical model and the clinical determinations.

\section{Mathematical Model}

A mathematical model was constructed to predict the $\mathrm{F}_{\mathrm{O}_{2}}$, given the clinically determined variables of tidal volume, respiratory rate, inspiratory fraction, oxygen flow rate, etc. Details of the design of this mathematical model will be presented in a separate publication." 


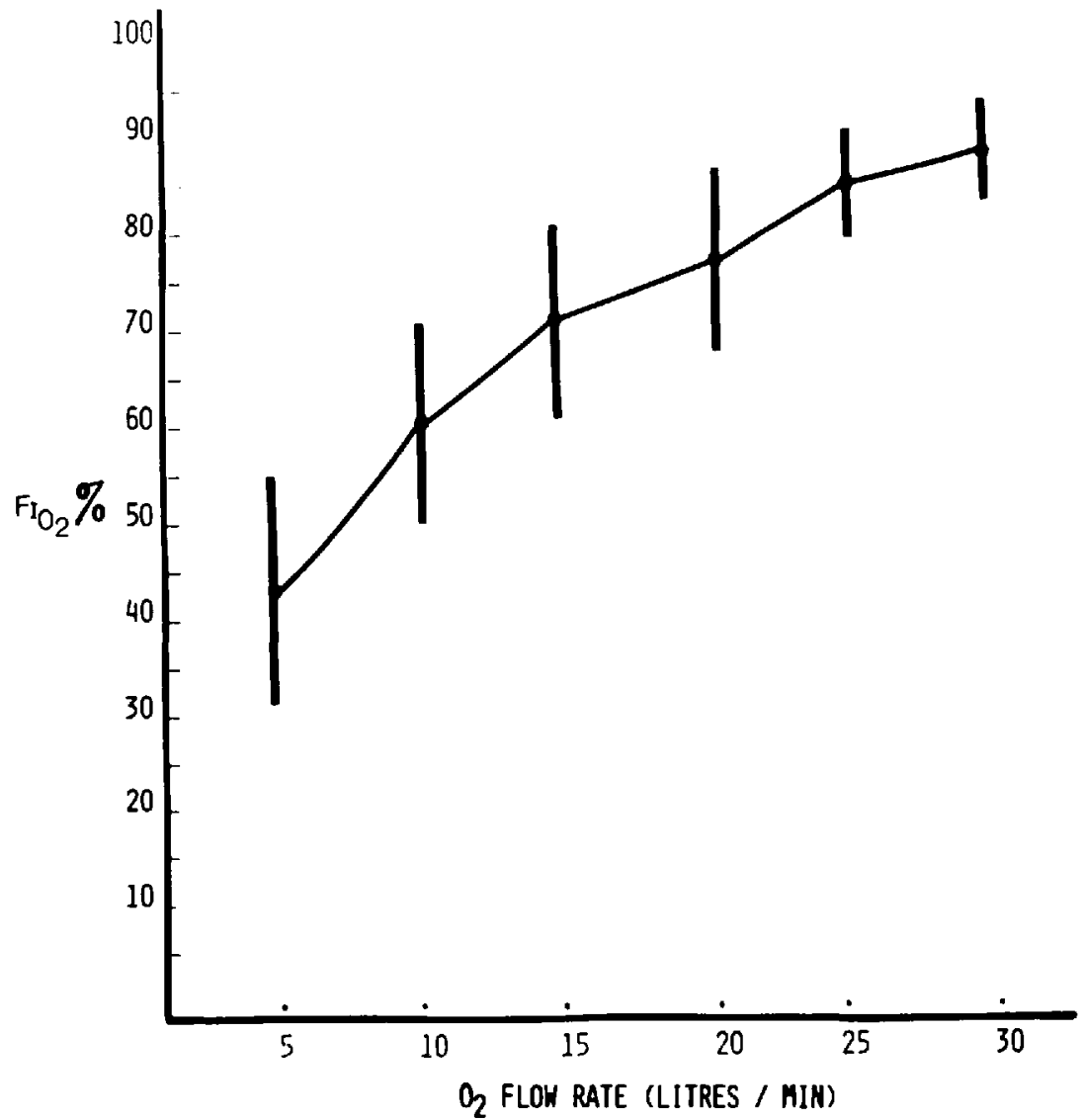

Figure 6. Clinical results using standard mask in ten patients. The standard deviations illustrate the considerable variability from patient to patient.

\section{Results}

Figure 6 shows results obtained in clinical studies using the standard face mask. The tracheal oxygen concentration increases with increasing flow rates of delivered oxygen, as would be expected. However, even at high flow rates, there is marked variation in $\mathrm{F}_{\mathrm{O}_{2}}$ from patient to patient (as reflected by the standard deviation). In addition, tracheal oxygen concentration never reaches 100 per cent but rather appears to plateau as the flow rate of oxygen to the mask is increased.

Figure 7 shows the result obtained with the mechanical model using the standard face mask in both a still and a turbulent environment. In the turbulent environment (with the fan on), the $\mathrm{FI}_{\mathrm{O}_{2}}$ varies considerably and unpredictably. 
MECHAIIICAL MODEL - AEROSOL MASK

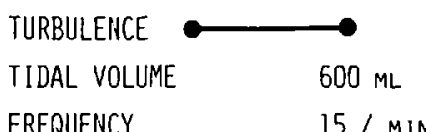

INSPIRATORY FRACTION .5

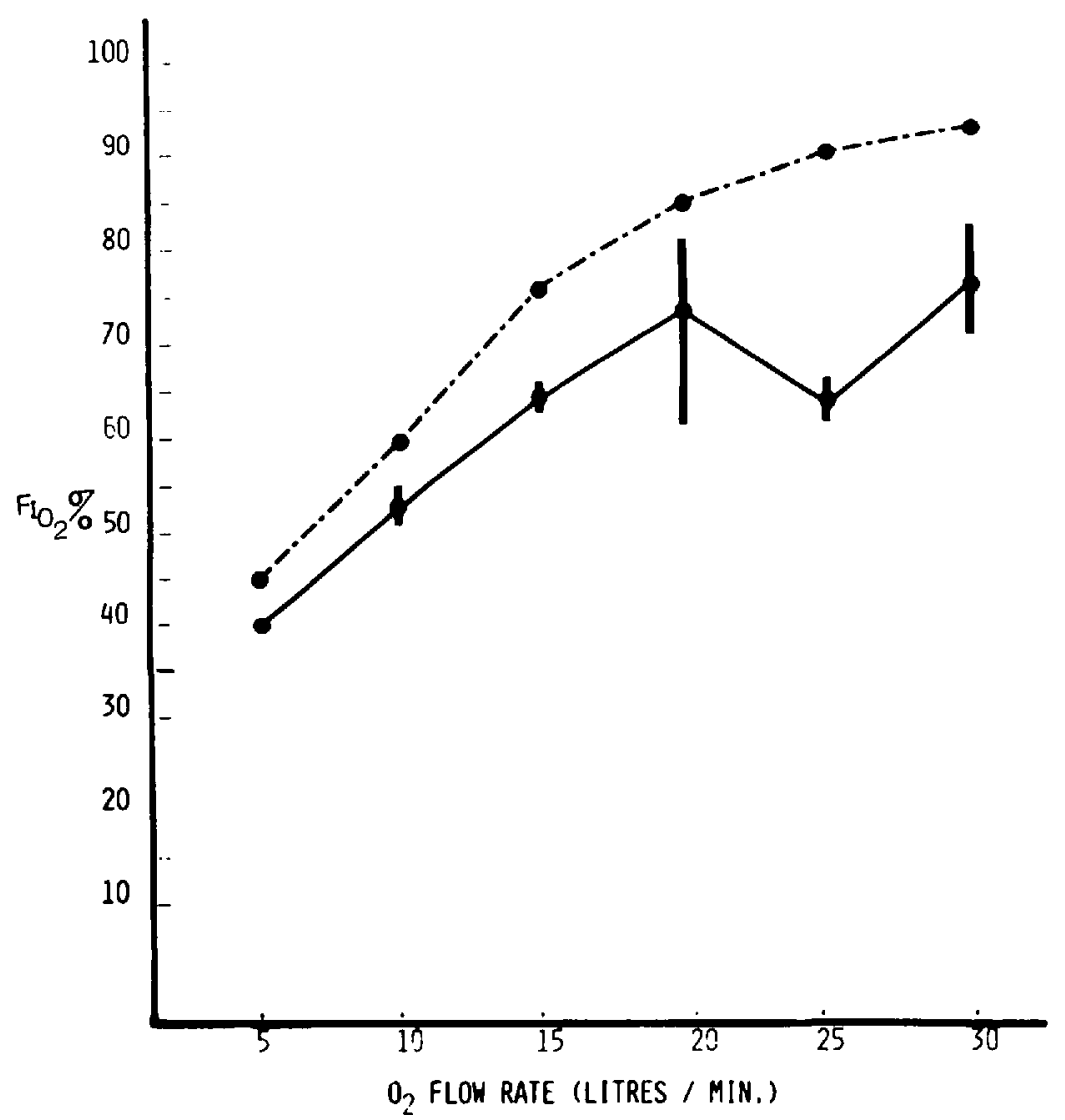

Figure 7. Measured $\mathrm{FI}_{\mathrm{O}_{\mathrm{g}}}$ using mechanical model and standard mask. Each point represents the average of five duplicate determinations. Presence of variations in repeated determinations represented by a vertical bar showing range of values. Note large variations of $F_{I_{2}}$ in turbulent environment (bottom curve) versus more stable, higher values in quiet environment (top curve).

In the still environment (fan off), the $\mathrm{F}_{\mathrm{O}_{2}}$ is higher and more stable. However, in neither case did the oxygen concentration in the mechanical trachea reach 100 per cent, even with oxygen delivered to the face mask at a rate of 30 litres per minute.

Results obtained under similar circumstances with the shielded mask, are shown in Figure 8. These illustrate two important features of the modified mask. The first is that room air turbulence has no significant effect on the $\mathrm{F}_{\mathrm{I}_{2}}$ delivered with this mask. The second is that the $\mathrm{F}_{\mathrm{I}_{2}}$ delivered with this mask is higher at 


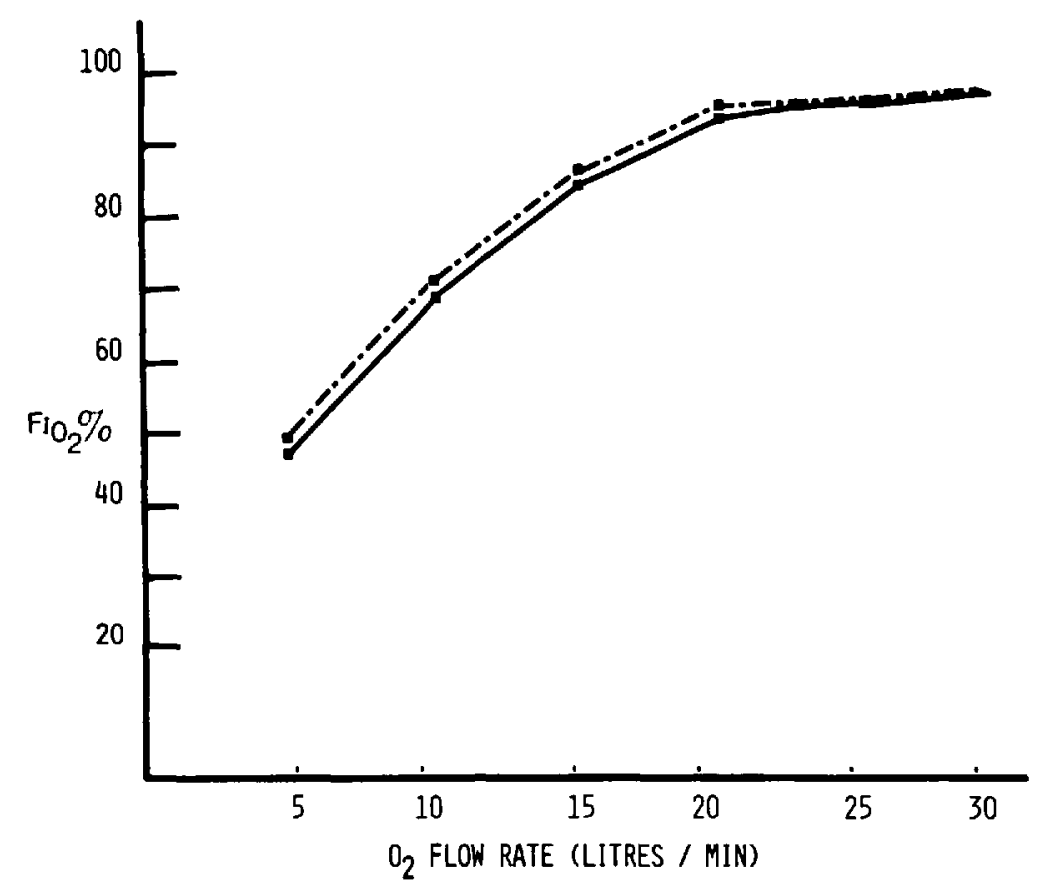

Frcure 8. Measured $\mathrm{F}_{\mathbf{I}_{0_{2}}}$ using mechanical model and shielded mask, Note stability of $\mathrm{F}_{\mathbf{I}_{2}}$ in both quiet and turbulent environment.

any given flow rate of oxygen delivery than the $\mathrm{F}_{\mathrm{O}_{2}}$ measured under similar circumstances with the unshielded mask. With the shielded mask, inspired oxygen concentration in the mechanical trachea reaches 100 per cent at an oxygen flow rate of 30 lites per minute. Even in the still environment, the $\mathrm{F}_{\mathbf{I}_{22}}$ delivered with the shielded mask is higher than that with the unshielded mask under similar circumstances. This is illustrated in Figure 9.

Clinical measurements of tracheal oxygen concentration were made on five patients using both the shielded and the standard mask on each patient. The results are shown in Figure 10 and demonstrate that the $\mathrm{FI}_{\mathrm{O}_{2}}$ obtained with the shielded mask were consistently higher than that obtained with the standard mask under similar cicumstances. When oxygen flow to the mask is 15 litres per minute or greater, the standard deviation from patient to patient using the shielded mask, 
MECHANICAL COMPARISON OF AEROSOL MASK AND SHIELDED MASK IN NON-TURBULENT ENVIRONMENT

AEROSOL MASK

TIDAL

VOLUME 600 ML $\bullet-\bullet \bullet$
SHIELDED MASK

TIDAL

VOLUME $600 \mathrm{ML}$

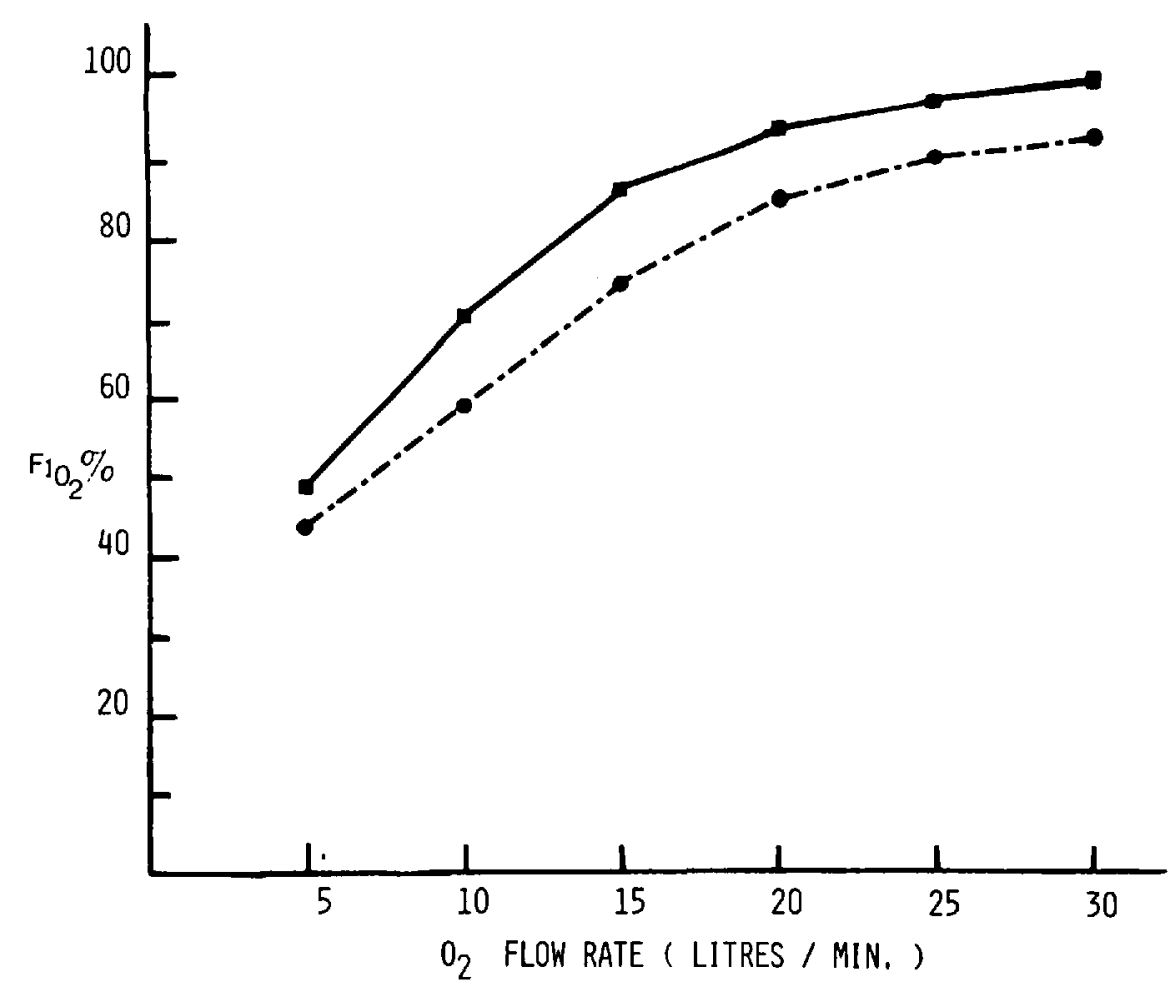

FIGURE 9. Mechanical model - standard $v s$ shielded mask in quiet environment. Note that the shielded mask gives a consistently higher $\mathrm{FI}_{\mathrm{O}_{2}}$ at all flow rates.

is significantly less than the standard deviation from patient to patient with the standard mask $(\mathrm{P}<0.005)$.

The clinically determined $F_{I_{0}, \text { was }}$ wampared with the value predicted by the mathematical model, using the clinically measured respiratory rate, tidal volume, etc. for each patient. This comparison was made for both the standard mask (Figure 11) and the shielded mask (Figure 12).

With the standard mask, the actual $\mathrm{F}_{\mathrm{I}_{2}}$ exceeded the predicted $\mathrm{F}_{\mathrm{I}_{2}}$ at oxygen flow rates of 15 litres per minute or less. At higher oxygen flow rates, the measured $\mathrm{F}_{\mathbf{I}_{1,2}}$ fell below mathematically predicted $\mathrm{F}_{\mathbf{I}_{\mathrm{O}} \text {. }}$. With the shielded mask, the actual $\mathrm{F}_{\mathbf{I}_{0,}}$ exceeded the predicted $\mathrm{F}_{\mathrm{I}_{0,}}$ at all flow rates. 


\section{Mean Inspired Oxygen Concentrations}

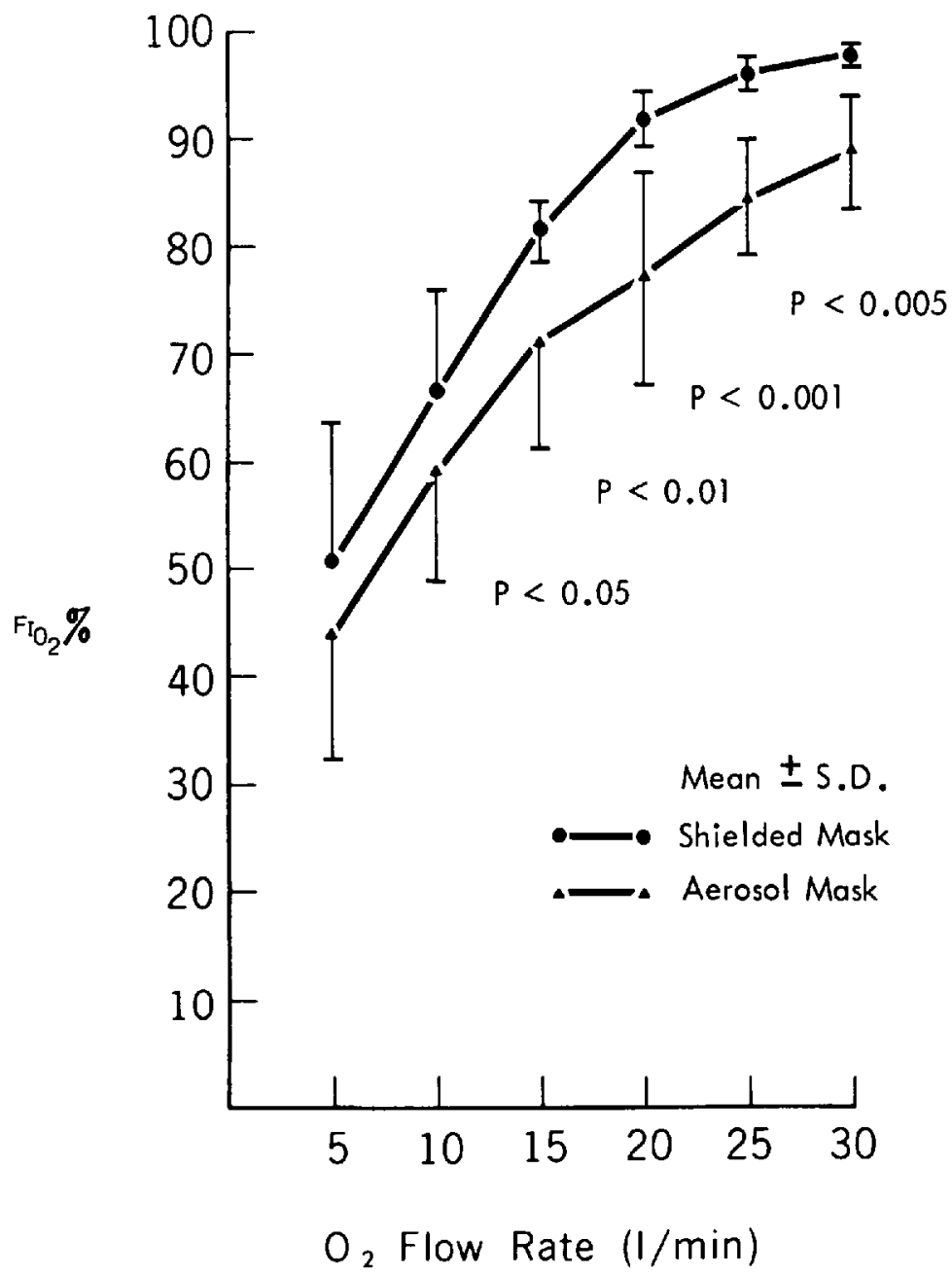

Figure 10. Comparison of standard mask with shielded mask in five patients. Note that with 15 litres per minute delivered $\mathrm{O}$. flow or greater there is significantly less variation of $\mathrm{F}_{\mathrm{IO}_{\mathrm{O}}}$ from patient to patient with the shielded mask compared with the standard mask (see p-values). Also the $\mathrm{F}_{\mathrm{I}_{2}}$ is consistently higher with the shielded mask, values reaching 100 per cent at 30 litres per minute in some patients.

\section{Discussion}

Several possibilities were initially considered to explain the clinical results obtained with the standard mask and the variation in the relationship between the clinically measured and the mathematically predicted $\mathrm{F}_{\mathrm{I}_{2}}$ shown in Figures 11 and 12. Certainly the respiratory pattern in the patient might change during the experiment and tidal volume during the experiment might not be the same as 
CLINICAL PREDICTABILITY OF INTRATRACHEAL OXYGEN CONCENTRATION AEROSOL MASK

RESERVOIR $=$ OML $\quad Y=26+0.66 X$

$R=0.82$

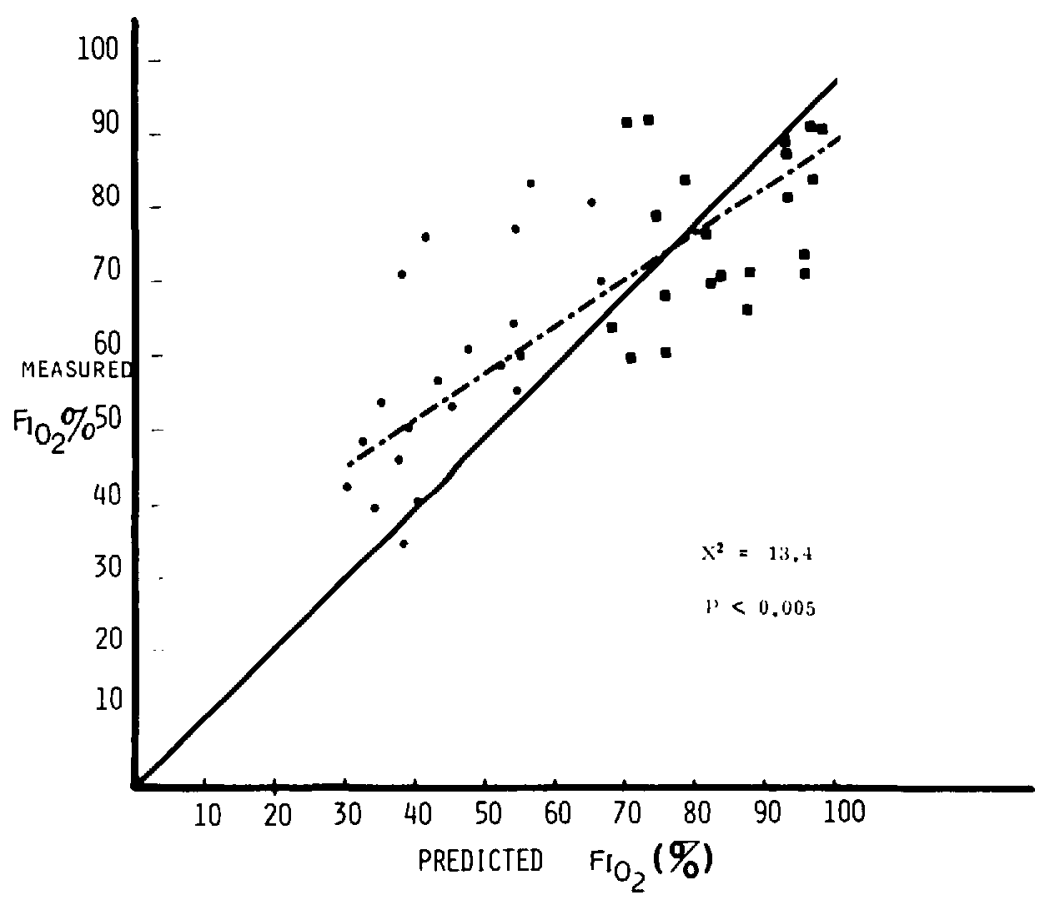

Ficure 11. Comparison of measured $\mathrm{F}_{\mathrm{O}_{2}}$ with mathematically predicted value using standard mask. Represent values at delivered $\mathrm{O}_{2}$ flow rates of 5 to 15 litres per minute. Represent values at delivered $\mathrm{O}_{2}$ flow rates of 20 to 30 litres per minute. Solid line is the line of identity's, broken line is that of best fit. Note change of relationship of predicted to measured at higher flow rates.

the tidal volume measured with the anaesthetic face mask before and after the experiment. The mathematical model also might not have taken into consideration factors or variables not apparent to us during the construction of this model.

The mechanical model was constructed in order to control these variables as much as possible. Even with the mechanical model, however, unexpected variations in the "tracheal" oxygen concentration occurred. It became apparent that there was a significant, though unpredictable, mixing of incoming oxygen in the mask with ambient room air. This mixing was over and above that attributable to the difference between the inspiratory flow rate and the flow rate of oxygen delivered to the mask. The unpredicted intermingling in the mask of room air and incoming oxygen was felt to arise from turbulence from two sources; air currents in the room around the face mask, and turbulence generated within the oxygen mask itself, caused by the incoming stream of oxygen.

Shielding the side holes in the oxygen mask was found to eliminate effect of 


\section{CLINICAL PREDICTABILITY OF INTRATRACHEAL OXYGEN CONCENTRATION}

SHIELDED MASK

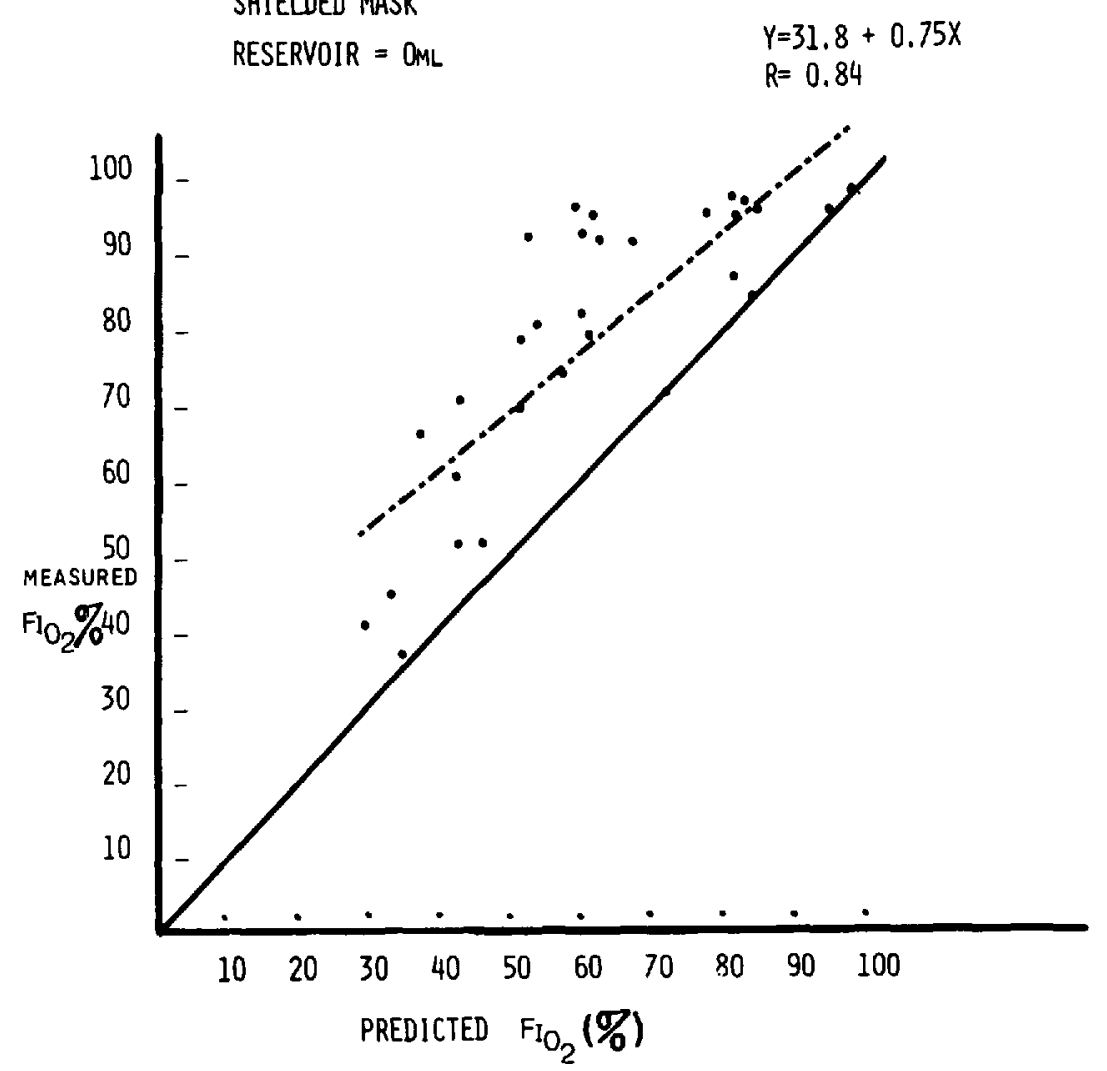

Figure 12. Comparison of measured $\mathrm{Fi}_{\mathrm{o}_{\mathrm{a}}}$ mathematically with predicted value using shielded mask. Represent all $\mathrm{O}_{2}$ flow rates of 5 to 30 litres per minute. Solid line is line of identity, broken line is that of best fit. Note that measured values consistently exceed predicted value. at all delivered $\mathrm{O}_{2}$ flow rates.

both room air turbulence and turbulence generated by the incoming stream of oxygen.

In patients, it was possible to obtain a higher $\mathrm{F}_{\mathrm{I}_{2}}$ with the shielded mask than was possible with the standard mask. With the shielded mask, the tracheal oxygen concentration could be raised to 100 per cent with a sufficiently high flow rate of oxygen delivery. This was not possible with the unshielded mask. The greater standard deviations at delivered flow rates of less than 15 litres per minute using a shielded mask, probably represents true breath-to-breath variations in a situation where the delivered oxygen flow does not approximate inspiratory flow requirements. In addition, delivered gas flow rates of less than 10 litres per minute can lead to $\mathrm{CO}_{2}$ retention in any plastic mask. ${ }^{6}$

It might be possible to obtain the beneficial features of the shielded mask, using currently existing masks which have either multiple small side holes or disc valves in the side holes. We did not evaluate such masks, however. When such masks are properly fitted to the patient, we have been able to demonstrate the production of large negative pressures (up to $-40 \mathrm{~cm} \mathrm{H}_{2} \mathrm{O}$ ) within these masks 


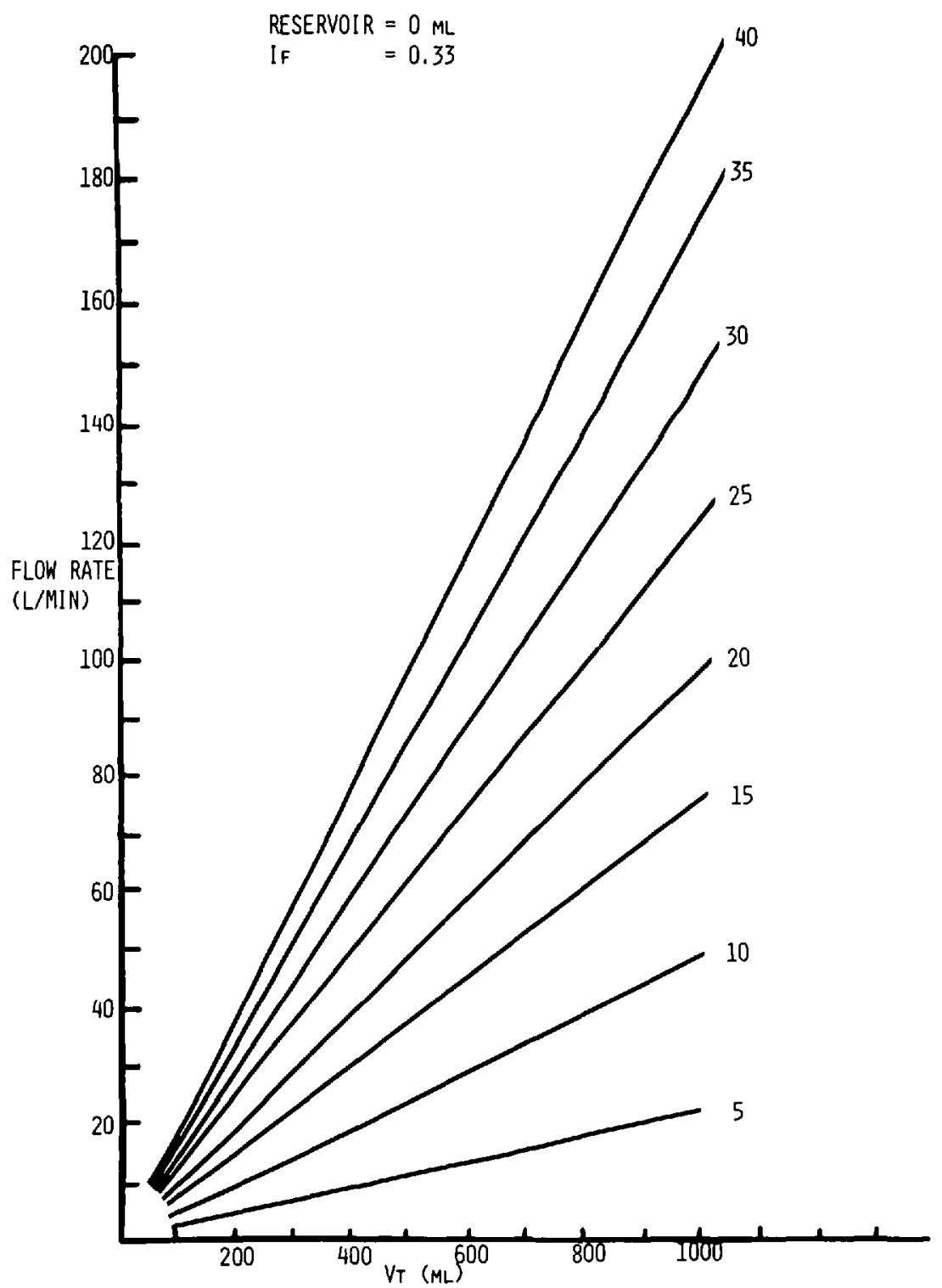

Figure 13. Nomogram to approximate maximum inspiratory flow rate. Each diagonal line represents a different respiratory frequency. Tidal volume $\left(V_{T}\right)$ is plotted in $m l$ on the $x$-axis. Maximum inspiratory flow rate is plotted on the $\mathrm{Y}$-axis in litre per minute. If the desired concentration of $\mathrm{O}_{2}$ is delivered to the patient at this flow rate using a shielded mask, the $\mathrm{F}_{\mathrm{I}_{0}}$ will closely approximate the delivered $\mathrm{O}_{2}$ concentration.

with either coughing or deep breathing. This would indicate an undesirable restriction of gas flow in and out of such a mask. This does not occur with the shielded mask.

Using the shielded mask, it is possible to deliver 100 per cent oxygen to the lungs if the incoming flow rate of oxygen is sufficiently high. To eliminate the 
potential risk associated with an unnecessarily high $\mathrm{Fr}_{\mathrm{O}_{2}}$, and to achieve a constant and predictable $\mathrm{F}_{\mathrm{I}_{2}}$, it is advisable to deliver the desired concentration of oxygen to the shielded mask, and to set the flow rate high enough to ensure that

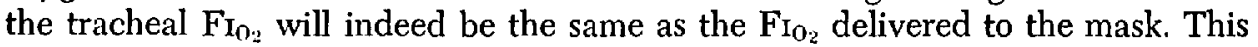
occurs when the incoming flow of gas to the mask is equal to or greater than the patient's maximum inspiratory flow rate.

Using the mathematical model, we have constructed a nomogram which gives a value for the maximum inspiratory flow rate of a patient from measurement of the respiratory rate and tidal volume. The nomogram has a fixed inspiratory fraction of 0.33 . The nomogram is shown in Figure 13. If the desired concentration of oxygen is administered to the shielded mask, at a flow rate equal to or greater: than that shown by the nomogram, the true inspired $\mathrm{F}_{\mathrm{I}_{\mathrm{O}}}$ will closely approximate the $F_{I_{():}}$delivered by the system. This method of delivering controlled concentrations of oxygen requires relatively high flow rates. With the Puritan nebulizer commonly used to deliver oxygen concentrations of 40 per cent or 70 per cent, high flow rates to the oxygen mask are relatively easy to achieve. If the nebulizer is set at 40 per cent, a flow of 10 litres of 100 per cent oxygen into the nebulizer leads to delivery of 40 litres per minute of 40 per cent oxygen to the face mask. If the nebulizer is set to deliver 70 per cent oxygen, 20 litres of 100 per cent oxygen into the nebulizer leads to a flow rate of 32 litres per minute of 70 per cent oxygen to the face mask.

\section{Summary}

Direct measurement of the inspired tracheal oxygen concentration was made in patients breathing through standard aerosol face masks. Factors affecting the tracheal $\mathrm{F}_{\mathrm{I}_{2}}$ were analyzed using both mechanical and mathematical models. When oxygen is delivered to the face mask at low flow rates, there is considerable patient variation in the measured tracheal $\mathrm{F}_{\mathrm{I}_{2}}$. Delivery of oxygen at higher flow rates ( 15 litres per minute or greater), reduces such variation. Furthermore, turbulent air currents within and around the face mask reduce the measured $\mathrm{FI}_{\mathrm{O}_{2}}$ and contribute to fluctuations in the $\mathrm{F}_{\mathrm{I}_{2}}$. This effect may be virtually eliminated by placing shields around the mask orifices as described. Using the shielded mask, it is possible to deliver the desired oxygen concentration to the patient more accurately and to maintain humidification of the delivered gases. Changes desired in inspired oxygen concentration are accomplished by changing the concentration of the incoming gas mixture, and not by merely changing the flow rate of oxygen delivered to the system.

Using the shielded mask, it is possible to deliver an inspired oxygen concentration of 100 per cent. This is not true with most other commonly used face masks, and, therefore, caution should be used to avoid administration of unnecessary high inspired oxygen concentrations with this type of mask.

\section{RÉsUMÉ}

Grâce à des prélèvements de gaz inspirés au niveau de la trachée, on a pu déterminer la concentration de l'oxygène chez des malades respirant à l'aide de masque à aérosol et l'on a pu analyser les différents facteurs susceptibles de 
modifier cette concentration d'oxygène trachéal, au moyen des modèles mécaniques et mathématiques.

On a trouvé que le débit de l'oxygène arrivant au masque est d'importance considérable: en effet, à bas débits, on observe des variations très importantes de la concentration d'oxygène d'un malade à l'autre, alors que des débits de 15 litres et plus minimisent ces variations.

De plus, on a observé que la turbulence de l'air dans le masque et autour de celui-ci contribue à réduire les concentrations d'oxygène à la trachée et provoque de grandes variations d'un malade à l'autre. A toutes fins pratiques, on peut éliminer les effets de la turbulence en plaçant des protecteurs vis-à-vis les orifices du masque. Avec un masque ainsi protégé, il devient possible de fournir les concentrations d'oxygène voulues de façon plus précise et d'assurer l'humidification des gaz. Avec ce masque, il devient même possible de fournir une concentration d'oxygène à 100 pour cent, ce qui est difficilement réalisable avec les masques communément employés. Il faut donc se souvenir de la possibilité d'administrer de l'oxygène à concentration trop élevée avec ce genre de masque.

\section{REFERENCES}

1. West, J.B. Ventilation/blood flow and gas exchange. Oxford, Blackwell (1970).

2. Mongan, A.P. The pulmonary toxicity of oxygen. Anaesthesiology 29: 570-579 (1968).

3. Burgess, A.M. A comparison of common methods of $\mathrm{O}_{2}$ therapy. Amer. J. Nurs. 65: 96-99 (1965).

4. Today's drugs: a rational approach to oxygen therapy. B.M.J. 5424: 1580-1582.

5. Flenley, D.C., Hutchison, D.C.S., \& Donald, K.W. Behaviour of apparatus of oxygen administration. M.B.J. 5365: 1081-1088 (1963).

6. Bethune, D.W. \& Collis, J.M. The evaluation of oxygen masks. Anaesthesia 22: 43-54 (1967).

7. NunN, J.F. Applied respiratory physiology. P. 300, Butterworths (1969).

8. Shapiro, B.A. Clinical application of blood gases. Year Book, Chicago (1973).

9. Wexler, H.R., Levy, H., Cooper, J.D., \& Aberman, A. A mathematical model to pre$\operatorname{dict} \mathrm{F}_{\mathrm{I}_{02}}$ : description and validation. C.A.S.J. $22: 410$ (1975). 